\title{
Correction to: Traveling wave solutions for degenerate nonlinear parabolic equations
}

\author{
Yu Ichida ${ }^{1} \cdot$ Takashi Okuda Sakamoto $^{1}$
}

Published online: 29 August 2020

(c) Orthogonal Publisher and Springer Nature Switzerland AG 2020

\section{Correction to: Journal of Elliptic and Parabolic Equations https://doi.org/10.1007/s41808-020-00080-y}

The article listed above was initially published with typo error in below matrix

$$
(0,0):\left(\begin{array}{ll}
0 & 0 \\
0 & 0
\end{array}\right), \quad(0, c):\left(\begin{array}{cc}
0 & 0 \\
0 & -c^{2}
\end{array}\right) .
$$

-P. 10, Line 9;

"It implies that there exists a function $h(\phi)$ satisfying" should be "It implies that there exists a function $h(\tilde{\phi})$ satisfying".

The matrix is corrected in original article.

Publisher's Note Springer Nature remains neutral with regard to jurisdictional claims in published maps and institutional affiliations.

The original article can be found online at https://doi.org/10.1007/s41808-020-00080-y.

Takashi Okuda Sakamoto

sakamoto@meiji.ac.jp

Yu Ichida

ce196001@meiji.ac.jp

1 Graduate School of Science and Technology, Meiji University, 1-1-1, Higashimita Tama-ku, Kawasaki, Kanagawa 214-8571, Japan 